\title{
LIFE HEALTHCARE ESIDIMENI: A (HUMAN RIGHTS) DREAM DEFERRED
}

\author{
Leoni van der Merwe* \\ LLB LLM \\ Lecturer, Faculty of Law \\ University of Johannesburg
}

\section{SUMMARY}

This article delves into South Africa's compliance with its obligations in terms of the United Nations Convention on the Rights of Persons with Disabilities in light of the deaths of 144 mental health patients transferred from the Life Healthcare Esidimen facility to various nongovernmental organisations during 2016. Consideration is given to South Africa's constitutional framework as well as the overall enforcement mechanisms and application of the said Convention in Africa given the existence of unique challenges such as HIV/AIDS, poverty and a scarcity of resources. The article recognises the importance of transcending beyond policy development, approval and publication to improve the lives of persons with disabilities in South Africa.

\section{$1 \quad$ INTRODUCTION}

During the period March 2016 to June 2016, the Gauteng Department of Health engaged in the process of rapidly transferring approximately 1371 persons with mental disabilities from the Life Healthcare Esidimeni facility to various hospitals and nongovernmental organisations (NGOs). The termination of the agreement between the Gauteng Department of Health and Life Healthcare Esidimeni necessitated the transfer. On 16 September 2016, Member of the Executive Council, Qedani Mahlangu, announced that 36 of the mental healthcare patients (the patients) transferred from Life Healthcare Esidimeni had died. At present, the news that 144 persons with mental disabilities died subsequent to being transferred from Life Healthcare Esidimeni has been met with indignation at a national and international level. Although the deaths that were reported, subsequent to the termination of the Life Healthcare Esidimeni agreement, led to Qedani Mahlangu's resignation and an investigation conducted by the Office of the Health Ombud, what remains to be observed is the meting out of accountability, and corresponding consequences to those complicit in the deaths of the patients concerned.

The emergence of allegations relating to the patients being without the requisite medicine for a period of two weeks and being housed in facilities 
that were inadequately licensed ${ }^{1}$ requires a critical appraisal of the human rights afforded to the patients in question. South Africa signed and ratified the United Nations Convention on the Rights of Persons with Disabilities (CRPD) in 2007 with the aim to promote, protect and ensure the full and equal enjoyment of all human rights and fundamental freedoms by all persons with disabilities and to promote their inherent dignity. ${ }^{2}$ According to Walker, the CRPD exemplifies what modern human rights instruments should be able to accomplish as it outlines key steps and actions to be taken by state parties to promote and protect the human rights of persons with disabilities. ${ }^{3}$

Although the Life Healthcare Esidimeni tragedy has been met with criticism and ire, the abuse and mortality of patients in mental health facilities, globally, is not novel as persons with disabilities are at higher risk of abuse due to their dependence on caregivers as well as the prevalence of certain barriers to communication. In England, nine children and young adolescents are known to have died in the care of various mental care facilities from 2010 to $2016 .{ }^{4}$ In the United States of America, the Occupational Safety and Health Administration has launched investigations into four Boston-area psychiatric hospitals for patient care violations as well as concerns relating to the safety of workers. ${ }^{5}$ Despite the public outrage regarding this matter, as at June 2017, many families of the deceased were yet to receive death certificates and numerous NGOs still remain open and are yet to be investigated. 9 October 2017 marked the commencement of an arbitration process, led by retired Deputy Chief Justice Dikgang Moseneke, into the deaths of the patients subsequent to their transfer from the Life Healthcare Esidimeni facility. The said arbitration was undertaken as per the recommendations of the Health Ombud, Malegapuru Makgoba, and sheds light on harrowing accounts of abuse, mistreatment and suffering of deceased patients as retold by relatives. ${ }^{6}$ While the findings of the arbitration proceedings are expected on 19 March 2018, with a view to providing the families of the deceased with financial compensation, the lessons learnt from

* The author extends her gratitude to the Dean of the Law Faculty of the University of Johannesburg, Professor GL Mpedi, for his invaluable mentorship during the preparation of this article.

1 Green "More Esidimeni Deaths, But None From Neglect" 21 April 2017 Health-E News https://www.health-e.org.za/2017/04/21/esidimeni-deaths-none-neglect/ (accessed 201706-12).

2 Walker "The United Nations Convention on the Rights of Persons with Disabilities: An Overview" in Library of Parliament (2013) 1.

3 Ibid.

4 Harpin "Tragedy as Nine Young People Died while Patients in Mental Health Units" 10 April 2016 The Mirror http://www.mirror.co.uk/news/uk-news/tragedy-nine-young-people-died7729668 (accessed 2017-01-20).

5 Burrell "OHSA launches 4 more investigations at Arbour Psychiatric hospitals" 11 November 2016 WGBH News http://news.wgbh.org/2016/11/11/local-news/osha-launches-4-moreinvestigations-arbour-psychiatric-hospitals (accessed 2017-03-23)

6 Mpofu "Life Esidimeni Arbitration: 143+ and Counting?" 18 December 2017 https://www.spotlightnsp.co.za/2017/12/18/life-esidimeni-arbitration-143-counting/ (accessed 2018-02-01). The arbitration hearing heard the testimony of Joseph Maboe who stated that his son was so emaciated when they visited him that he ate the plastic packet of the chips that they brought him to eat and he subsequently died two days later. Additionally, Ntombifuthi Dladla also provided testimony regarding the manner in which she found her brother's decomposed body. 
this matter are of paramount importance in improving the lives of many persons with disabilities, nationally and internationally.

Against this brief background, this article provides an assessment of South Africa's adherence to the provisions of the CRPD with a specific focus on the Life Healthcare Esidimeni matter. The author will consider South Africa's broader constitutional framework, the structure of the CRPD, its enforcement mechanisms and application in Africa given the continent's unique challenges relating to, inter alia, poverty, disease and resource scarcity. A comparison will then be made between the findings of the Health Ombudsman regarding this matter and specific provisions of the CRPD such as respect for inherent dignity and protecting the integrity of the person; equality and non-discrimination; the right to life; freedom from torture or cruel, inhuman or degrading treatment or punishment; freedom from exploitation, violence and abuse; health; an adequate standard of living; and habilitation and rehabilitation. The author recommends that existing policy and constitutional provisions be utilised to strengthen South Africa's compliance with the CRPD.

\section{CONSTITUTIONAL FRAMEWORK}

South Africa's compliance with its obligations in terms of the CRPD is to be regarded against the framework of the Constitution of the Republic of South Africa, 1996 (hereinafter "the Constitution"). Section 9 of the Constitution prohibits the state and any person from, directly or indirectly, discriminating against anyone based on disability and places an onus on the state to enact legislation to prevent and prohibit unfair discrimination. Although various pieces of legislation have been enacted to advance the rights of persons with disabilities in South Africa; ${ }^{7}$ it has been argued that South Africa's failure to promulgate a single, comprehensive piece of disability legislation, ${ }^{8}$ poor monitoring of legislative compliance and the incorrect interpretation of the law have led to an inability to alleviate the challenges experienced by persons with disabilities relating to infrastructure, employment, healthcare, education and the like.

Central to the Life Healthcare Esidimeni matter is the responsibility placed on the state, in section 27 of the Constitution, to take reasonable legislative and other measures within its available resources, to achieve the progressive realisation of the right to access healthcare, sufficient food, water and social security. Brand and Heyns highlight that while section 27 does not give rise to an unrealistic, absolute, on-demand entitlement to the rights in question; the state cannot utilise the absence of such an absolute entitlement as a means to delay the receipt of the rights contained in section $27 .^{9}$ The relationship between the right to access to healthcare services as

7 See Employment Equity Act 55 of 1998 and The Promotion of Equality and Prevention of Unfair Discrimination Act 4 of 2000.

8 Sibanda "The State of Disability Rights - Is South Africa Doing Enough?" in The Repository of The Centre for Constitutional Rights (undated) 1; The absence of comprehensive disability legislation is in stark contrast to the position in jurisdictions such as Malawi, Canada, Nigeria and the United Kingdom.

9 Heyns and Brand "Introduction to Socio-economic Rights in the South African Constitution" 19982 Law, Democracy and Development 153. 
contained in section 27 of the Constitution and the right to life requires consideration. In the case of Soobramoney $v$ Minister of Health KwazuluNatal, ${ }^{10}$ the court held that although the obligations imposed on the state by section 27 of the Constitution are dependent upon the availability of resources as allocated by the state, provision has been made in section 27(3) of the Constitution to ensure that emergency medical treatment is provided for the purpose of prolonging life, where immediate remedial treatment is required.

With regard to the application of international law, section 39(1)(b) of the Constitution provides that:

"When interpreting the Bill of Rights, a court, tribunal or forum must consider international law."

While the courts have previously considered the role of international law in the interpretation of the Bill of Rights, ${ }^{11}$ the interpretation of international law provisions relating to persons with disabilities receives limited attention, which could lead to inconsistencies in the application instruments such as the CRPD. What is required, at a national level, is the continuous monitoring of the consistent application of international law instruments when interpreting rights contained in the Bill of Rights. Such a monitoring process will serve to alleviate the overall challenges experienced regarding the inconsistent interpretation of international law instruments as highlighted by Tladi. $^{12}$

\section{STRUCTURE AND ENFORCEMENT OF THE CRPD}

South Africa's ratification of the CRPD in 2007, as a tool to promote the realisation of the rights of persons with disabilities, marks a stark contrast to its exclusion from the international disability community preceding 1994 due to the government's racial segregation policies. ${ }^{13}$ The adoption of the CRPD is the culmination of decades of research conducted by the United Nations in furtherance of the transition from the medical to the social model of disability. The medical model presupposes that disability is mainly a health and welfare matter with an individualistic and dependency-based approach at its nucleus. The social model, however, implies a paradigm shift in the manner in which disability is constructed to highlight the shortcomings of society in respect of disability and to bring to the fore the capabilities of persons with disabilities. An increased commitment by the international community in relation to disability issues as well as an amplified understanding of the role played by disability as a component of successful development have been identified as instrumental factors leading to the development of the CRPD. ${ }^{14}$

\footnotetext{
19981 SA 765 (CC).

1 See generally, S v Makwanyane 1995 (6) BCLR 665 (CC); Glenister v President of the Republic of South Africa 2011 (3) SA 347 (CC).

12 Tladi in Aust and Nolte (eds) The Interpretation of International Law by Domestic Courts: Uniformity, Diversity, Convergence (2016) 145.

13 Barnes "International Isolation and Pressure for Change in South Africa" 199019 Accord 36.

14 Guernsey, Nicoli and Ninio "Convention on the Rights of Persons with Disabilities: Its Implementation and Relevance for the World Bank" in The World Bank Social Protection
} 
During its first day of enactment, the CRPD garnered a record-breaking 82 signatories, which is partially attributable to the inclusion of stakeholders, specifically civil society, at all stages of the drafting process, including the end-stage negotiations that are typically reserved for government delegations. ${ }^{15}$ The CRPD comprises 50 articles that explain the obligations of state parties in relation to persons with disabilities. Ancillary to the CRPD is the Optional Protocol to the CRPD (the Optional Protocol) that makes provision for the receipt and consideration of "communications" from or on behalf of individuals or groups of individuals who claim to be victims of a violation by a state party.

Article 1 of the CRPD provides that:

"The purpose of the present Convention is to promote, protect and ensure the full and equal enjoyment of all human rights and fundamental freedoms by all persons with disabilities, and to promote respect for their inherent dignity. Persons with disabilities include those who have long-term physical, mental, intellectual or sensory impairments, which in interaction with various barriers may hinder their full and effective participation in society on an equal basis with others."

The monitoring and implementation of the CRPD takes place nationally and internationally in terms of articles 33 and 34, respectively. Article 34 of the CRPD makes provision for the designation of a focal point within the government of a state party to address the implementation of the CRPD across various sectors and levels of government. Additionally, state parties are required to establish a framework to promote, protect and monitor the implementation of the CRPD.

At an international level, article 34 of the CRPD provides for the establishment of a Committee on the Rights of Persons with Disabilities (hereinafter "the Committee") to provide, inter alia, oversight in respect of requisite reports by state parties as well as reports from the Committee, to the United Nations General Assembly, containing suggestions and recommendations based on information received from state parties. ${ }^{17}$ Further to the duties of the Committee, article 1 of The Optional Protocol recognises the competence of the Committee to receive and consider communications from or on behalf of individuals and groups of individuals who claim to be victims of a violation by a state party. ${ }^{18}$ The Optional Protocol allows the Committee to commence inquiry procedures into grave or systemic violations by state parties, which may result in state parties

Discussion Paper (2007) $3 \mathrm{http}: / /$ siteresources.worldbank.org/SOCIALPROTECTION/

16 United Nations General Assembly Resolution 106 (2007-01-24) UN Doc A/RES/61/106.

Ibid.

18 Article 1 of the CRPD Optional Protocol is to be read with article 4 of the same protocol which provides that: "1 At any time after the receipt of a communication and before a determination on the merits has been reached, the Committee may transmit to the State Party concerned for its urgent consideration a request that the State Party take such interim measures as may be necessary to avoid possible irreparable damage to the victim or victims of the alleged violation. 2 Where the Committee exercises its discretion under paragraph 1 of this article, this does not imply a determination on admissibility or on the merits of the communication". 
being required to respond to such proceedings with relevant observations within a six-month period.

At a national level, the Department of Women, Children and Persons with Disabilities (DWCPD) was established in 2009 to coordinate and consolidate the promotion of the rights of women, children and persons with disabilities in South Africa. The core functions of the Disability Unit of the DWCPD was to facilitate transversal policy implementation to further the empowerment, advancement and socio-economic development of persons with disabilities; to ensure the consideration of disability-related issues in governmental policies, processes and programmes; and to facilitate and coordinate the various reporting requirements as per national and international requirements. ${ }^{19}$ The DWCPD has received assistance from the United Nations in support of the former's legal and policy development efforts to accelerate compliance with national and international obligations in respect of persons with disabilities as well as the rejuvenation of efforts towards implementing the CRPD. ${ }^{20}$

\section{APPLICATION OF THE CRPD IN AFRICA}

While, the global strides intended by the CRPD in transitioning from the medical model of disability to the social model are apparent; ${ }^{21}$ a closer inspection of the CRPD's effectiveness in Africa requires consideration to ensure a holistic, open-minded and fair assessment of South Africa's compliance with its obligations under the CRPD.

Two opposing views have been identified regarding the application of the CRPD in Africa. Firstly, it has been suggested that an African-centric disability protocol be developed that is similar to the CRPD but that takes into account issues pervasive in Africa such as resource restrictions, poverty, HIV/AIDS and slow levels of development. This approach is predominantly motivated by the prior creation of regional international law instruments such as the African Charter on the Rights and Welfare of a Child that was drafted and modelled according to United Nations Convention on the Rights of a Child. ${ }^{22}$

Conversely, the view is held that the inclusive role played by African states during the drafting process of the CRPD $^{23}$ provided many opportunities for the consideration of various regional challenges faced within an African context. It must, however, be noted that the success of an international law instrument relating to persons with disabilities, whether at a regional or broader level, is dependent on the creation, implementation and

19 United Nations Country Team, South Africa "Accelerating the implementation of the UNCRPD in South Africa" in United Nations Development Programme Repository (2011) 3.

20 Ibid.

21 Virtanen in Kumpuvuori and Scheinin (eds) United Nations Convention on the Rights of Persons with Disabilities - Multidisciplinary Perspectives (2009) 256.

22 Oyaro "Africa at Crossroads: The United Nations Convention on the Rights of Persons with Disabilities" 201530 American University International LR 347.

23 See Kanter "The Promise and Challenges of the United Nations Convention on the Rights of Persons with Disabilities" 200734 Syracuse Journal of International Law and Commerce 287. 
monitoring of domestic laws that give effect to and facilitate compliance with the said international law provisions.

It can be deduced that the application of the CRPD in Africa leads to a proverbial double-edged sword as it is only through the prioritisation of the CRPD, as enforced by corresponding domestic laws, that African states would be in a position to improve the immediate circumstances of persons with disabilities although a bespoke, African-centric disability protocol, that takes into consideration issues such as HIV/AIDS and poverty, would serve to benefit persons with disabilities in Africa in the longer term. In the interim, it remains crucial for African states to circumvent the application of international instruments such as the CRPD in a "copy and paste" fashion.

\section{5}

A CRITICAL APPRAISAL OF SOUTH AFRICA'S
COMPLIANCE WITH OBLIGATIONS IN TERMS
OF THE CRPD AND THE DEATHS OF 144
PERSONS WITH DISABILITIES SUBSEQUENT TO
THEIR TRANSFER FROM THE LIFE
HEALTHCARE ESIDIMENI FACILITY

For purposes of the research conducted, the author considered the Health Ombud of the Republic of South Africa's Report into the circumstances surrounding the deaths of 94 patients (hereinafter "the Report"). ${ }^{24}$ The Report is the culmination of a request by the Minister of Health, Aaron Motsoaledi, in terms of section $81 \mathrm{~A}$ of the National Health Amendment Act 12 of 2013, to the Health Ombud to undertake an investigation into the deaths of numerous patients subsequent to their transfer from the Life Esidimeni Healthcare facility. ${ }^{25}$ It must be noted that although there has been a surge of commentary regarding this matter, for purposes of verity, the Report will be regarded as the official version of findings relating to the Life Esidimeni Healthcare matter, as information contained in other sources cannot be corroborated. According to the Report, the deaths of 94 patients "cannot really be dissociated with the move" and it was subsequently concluded that all the patients died under unlawful circumstances. ${ }^{26}$

The CRPD is based on the following principles, as per article 3: respect for inherent dignity and individual autonomy; non-discrimination; full and effective participation and inclusion in society; respect for difference and acceptance of persons with disabilities as part of human diversity and humanity; equality of opportunity; accessibility; equality between men and women; respect for the evolving capacities of children with disabilities and respect for the right of children with disabilities to preserve their identities. As

24 Makgoba "The Report into the 'Circumstances surrounding the deaths of mentally ill patients: Gauteng Province'" (2017) https://www.sahrc.org.za/home/21/files/Esidimeni\% 20full\%20report.pdf

$25 \mathrm{~S} 81 \mathrm{~A}(1)$ of the National Health Amendment Act 12 of 2013 provides that: "The Ombud may, on receipt of a written or verbal complaint relating to norms and standards, or on his or her own initiative, consider, investigate and dispose of the complaint in a fair, economical and expeditious manner."

26 Makgoba "The Report into the "Circumstances surrounding the deaths of mentally ill patients: Gauteng Province"' (2017) 1. 
a point of departure, numerous general principles of the CRPD will be considered to determine South Africa's compliance with its obligations as a state party to the CRPD which will be followed by the consideration of specific rights relating to life; freedom from torture or cruel, inhumane or degrading treatment or punishment; freedom from exploitation, violence and abuse; integrity; health and adequate living standards and social protection. ${ }^{27}$

(i) Respect for the inherent dignity and protecting the integrity of the person

The promotion of respect for the inherent dignity of persons with disabilities is contained in not only the Preamble of the CRPD but also in its purpose as well as provisions relating to awareness raising; freedom from exploitation, violence and abuse; education and health. According to the Report, the precipitous decision to terminate the contract with Life Esidimeni Healthcare was contrary to the National Mental Health Policy, as the cost rationale for termination could not be justified above the right to dignity of the patients. The inhumane methods that were utilised to transport patients, where bed sheets were used as restraints and the likening of the process of selecting patients, by NGOs, to an auction cattle market are indicative of the lack of respect for dignity as contained in the CRPD.

It has further been acknowledged that:

"The conditions to which MCHUs were subjected to during the period of transfer from Life Healthcare Esidimeni and into the NGOs were negligent and devoid of respect for human dignity and rights." ${ }^{28}$

Article 17 of the CRPD stipulates that:

"Every person with disabilities has the right to respect for his or her physical and mental integrity on an equal basis with others.

Apart from at a regional treaty level, the inclusion of this right in the CRPD is regarded as the first kind of recognition of the right to respect for integrity at an international level. ${ }^{30}$ The provisions of regional instruments such as the African Charter on Human and People's Rights, the American Convention on Human Rights and the European Charter of Fundamental Rights may be utilised to provide guidance to state parties regarding the application of the right to respect for integrity as contained in the CRPD. According to the Report, it is incumbent on state parties to protect the personal integrity of persons with disabilities and that this requisite level of care was absent in this matter "as conceded by the parties and given the vulnerability of the MHCUs." ${ }^{31}$

United Nations General Assembly Resolution 106 (2007-01-24) UN Doc A/RES/61/106.

Makgoba "The Report into the 'Circumstances surrounding the deaths of mentally ill patients: Gauteng Province"” (2017) 36.

29 United Nations General Assembly Resolution 106 (2007-01-24) UN Doc A/RES/61/106 13.

30 Minkowitz "Freedom from Nonconsensual Psychiatric Interventions" 200734 Syracuse Journal of International Law and Commerce 405.

31 Makgoba "The Report into the 'Circumstances surrounding the deaths of mentally ill patients: Gauteng Province'" (2017) 49. 


\section{(ii) Equality and non-discrimination}

Article 4 of the CRPD recognises the need for persons with disabilities to be guaranteed the full enjoyment of human rights and fundamental freedoms without discrimination. ${ }^{32}$ Of importance is the acknowledgement contained in the Report of the role that stigma and discrimination in respect of persons with mental illness plays in their inhumane and degrading treatment. ${ }^{35}$

Akin to the promotion of equality and the elimination of discrimination contained in article 5 of the CRPD, is the responsibility of state parties to provide reasonable accommodation to persons with disabilities.

\section{Reasonable accommodation refers to}

"necessary and appropriate modification and adjustments not imposing a disproportionate or undue burden, where needed in a particular case, to ensure to persons with disabilities the enjoyment or exercise on an equal basis with others of all human rights and fundamental freedoms."

The Health Ombudsman's findings indicate that the NGOs where patients died were not able to provide for the highly specialised, continuous needs of patients and that staff lacked the requisite training. Alarmingly, certain NGOs such as Rebafenyi and Ubuhle Benkosi were established with the aim of carrying out initiatives in furtherance of the empowerment of women and the care of orphaned children, respectively, and were not suitable for the care of mentally ill patients. Based on the lack of coherence between the needs of patients and the fitness for purpose of NGOs, it is the author's submission that many of the deceased patients in question were not reasonably accommodated in their respective NGOs as required by article 5(4) of the CRPD. $^{35}$

\section{(iii) Right to life}

Article 10 of the CRPD reaffirms the right to life, which is widely recognised as a core principle of human rights law. ${ }^{36}$ The right to life serves as a prerequisite for the realisation and enjoyment of other rights in the CRPD. According to the United Nations, the right to life encompasses the right of living, which refers to the right of every human being to have the appropriate means of subsistence and a decent standard of life. ${ }^{37}$ The acknowledgement by the South African government that specific protective measures are required to ensure that the right to life of persons with disabilities are upheld ${ }^{38}$ can be juxtaposed against the findings contained in

32 United Nations General Assembly Resolution 106 (2007-01-24) UN Doc A/RES/61/106 5.

33 Makgoba "The Report into the "Circumstances surrounding the deaths of mentally ill patients: Gauteng Province'" (2017) 50.

34 United Nations General Assembly Resolution 106 (2007-01-24) UN Doc A/RES/61/106 4.

35 Article 5(4) of the CRPD provides that: "Specific measures which are necessary to accelerate or achieve de facto equality of persons with disabilities shall not be considered discrimination under the terms of the present Convention".

36 Lord "Screened Out of Existence: The Convention on the Rights of Persons with Disabilities and Selective Screening Policies" 20122 International Journal of Disability, Community and Rehabilitation http://www.ijdcr.ca/VOL12_02/articles/lord.shtml (accessed 2017-10-10).

37 Alvarez "The Right to Water as a Human Right" (unpublished paper) http://centerhre.org/wp-content/uploads/2011/05/the-right-to-water-as-a-human-right.pdf (accessed 2018-01-17).

38 GN 230 in GG 39792 of 2016-03-09. 
the Report that the transfer of patients to the NGOs was to an "unstructured, unpredictable, substandard caring environment." ${ }^{39}$ Furthermore, the overall pace and manner of transferring patients provides an overall indication of the absence of the said protective measures to ensure that the transition of patients took into consideration their overall wellbeing.

During December 2015, the South African Cabinet approved the White Paper on The Rights of Persons with Disabilities (WPRPD) with the aim to elevate the position of persons with disabilities in relation to their inclusion, integration and equality in society. Although the WPRPD does not bring about a policy shift insofar as the South African government's stance regarding persons with disabilities, it echoes the responsibilities of and coordination required amongst all spheres of government, society and persons with disabilities in accomplishing disability equity. The inclusion in the WPRPD of monitoring and evaluation as one of the nine strategic pillars on which the policy has been developed as well as the publication of an annual report by the designated national disability rights coordinating mechanism, to monitor progress made in disability transformation, is indicative of the introduction of an accountability-based reporting standard at a national level. This inclusion marks a departure from previous policy documentation such as the White Paper on the Integrated National Disability Strategy of 1997, which on the one hand, makes reference to the monitoring of legislation, spheres of government, and the Integrated National Strategy; but makes no mention of mechanisms to formally measure, record and track the implementation of mechanisms to improve the lives of persons with disabilities. Of interest, is a directive included in the WPRPD that recommends the creation of a monitoring system to track the loss of life due to insufficient measures being taken to protect the lives of persons with disabilities. ${ }^{40} \mathrm{~A}$ reliance on the aforementioned monitoring system could have promoted efficient communication with the relatives of the deceased patients, which was highlighted as a shortcoming of the Report. ${ }^{41}$

(iv) Freedom from torture or cruel, inhuman or degrading treatment or punishment

Article 15(1) of the CRPD provides that:

"No one shall be subjected to torture or to cruel, inhuman or degrading treatment or punishment.

An obligation is also placed on state parties to take legislative, administrative, judicial or other measures to prevent persons with disabilities from being subjected to torture or cruel, inhuman or degrading treatment or punishment. Globally, persons with disabilities are mistreated during their occupation of psychiatric hospitals, orphanages, nursing homes and other institutions and such mistreatment is attributed to neglect and a lack of

39 Makgoba "The Report into the 'Circumstances surrounding the deaths of mentally ill patients: Gauteng Province'" (2017) 1.

40 GN 230 in GG 39792 of 2016-03-09 116.

41 Makgoba "The Report into the 'Circumstances surrounding the deaths of mentally ill patients: Gauteng Province'" (2017) 33.

42 United Nations General Assembly Resolution 106 (2007-01-24) UN Doc A/RES/61/106 12. 
care. ${ }^{43}$ In addition to findings in the Report of inhuman and degrading treatment during the transportation of the patients, the Report contains additional information from the South African Human Rights Commission of allegations that patients died due to hunger and dehydration.

According to Ezer, Cohen and Quinn, the legal definitions of torture and other acts of cruel, inhuman and degrading treatment, as contained in international law instruments, broadly embrace a range of abuse in healthcare environments. ${ }^{44}$ Taking into consideration the responsibility placed on state parties by article 15(2) of the CRPD to implement effective legislative, administrative, judicial or other measures to prevent torture, it is apparent that the South African government failed to effectively safeguard patients from cruel, inhuman and degrading treatment during their transfer from Life Healthcare Esidimeni.

\section{(v) Freedom from exploitation, violence and abuse}

Article 16 of the CRPD places an onus on state parties to take all appropriate legislative, administrative, social, educational and other measures to protect persons with disabilities from all forms of exploitation, violence and abuse.

Although the term "abuse" is predominantly defined and utilised in the context of domestic violence, sexual offences and children's rights in international law, ${ }^{45}$ the definition of abuse as furnished by the United Nations High Commissioner for Refugees (UNHCR) could be utilised to gauge South Africa's compliance with this provision of the CRPD. According to the UNHCR, abuse is defined as "the process of making bad or improper use, or violating or injuring, or to take advantage of, or maltreat, the person." ${ }^{46}$ Comparisons between the accounts of the relatives of the deceased which likened certain NGOs to insecure, unsafe, filthy and poorly staffed concentration camps that were overcrowded with hungry and injured patients, ${ }^{47}$ and the previously-mentioned definition of abuse, provides a prima facie indication of abuse as well as non-compliance with article 16(1) of the CRPD. Additionally, the hasty, ham-handed approach to the movement of certain patients to NGOs that were licensed but were not fitfor-purpose or ready to accommodate patients is indicative of a failure to provide the NGOs with the tools required to allow them to care for patients.

(vi) Health and an adequate standard of living and social protection

The chapeau of article 25 of the CRPD provides that:

43 Rosenthal and Ahern "When Treatment is Torture: Protecting People with Disabilities in Detained Institutions" 201219 Human Rights Brief 13.

44 Ezer, Cohen and Quinn "The Problem of Torture in Healthcare" in Torture in Healthcare Settings: Reflections on the Special Rapporteur on Torture's 2013 Thematic Report (2013) 19.

45 See United Nations Convention on the Rights of a Child and Declaration on the Elimination of Violence against Women.

46 United Nations High Commissioner for Refugees "Critical issues: Abuse and Exploitation" (2008) 3.

47 Makgoba "The Report into the 'Circumstances surrounding the deaths of mentally ill patients: Gauteng Province'” (2017) 6. 
"State Parties recognise that persons with disabilities have the right to the enjoyment of the highest attainable standard of health without discrimination on the basis of disability. State Parties shall take all appropriate measures to ensure access for persons with disabilities to health services that are gendersensitive, including health-related rehabilitation."

In the subsequent subsections of article 25 , an onus is placed on states to provide persons with disabilities with the health services needed by the said persons as a result of their disabilities as well as to prevent discriminatory denial of healthcare or services or food and fluids based on disability. The receipt by persons with disabilities of the highest standard of healthcare and services transects with various rights contained in the CRPD and is therefore of paramount importance. According to Joly, the CRPD contains the most comprehensive explanation of the right to health of any human rights treaty currently in existence, which speaks to the drafter's awareness of the important role that health, can play in reversing the invisibility of persons with disability in society.

According to the Report, the cost-saving rationale provided for the swift termination of the Gauteng Department of Health's agreement with Life Healthcare Esidimeni paled in comparison to the obligation to provide the patients with access to adequate healthcare. Additionally; unskilled and untrained staff, a lack of competence or skill to administer medication, the irregular monitoring of patients' vital data, the lack of financial capacity which contributed to the inability to procure nutritious food and staff were identified as factors that compromised the overall quality of healthcare received by the patients "and made the patients vulnerable to death.".50

The responsibility to provide persons with disabilities with healthcare or services is to be read with article 28 of the CRPD, as the said provision requires that state parties recognise the right of persons with disabilities to an adequate standard of living, which includes adequate food, clothing and housing. A further onus is placed on state parties to ensure the continuous improvement of living conditions of persons with disabilities. The importance of this particular provision cannot be soft-pedalled due to the clear indication that persons with disabilities are more vulnerable to the vicious cycle of poverty and disability, each of which, as per Guernsey, Nicoli and Ninio, is both a cause and a consequence of the other. ${ }^{5}$

(vii) Habilitation and Rehabilitation

By virtue of article 26 of the CRPD, state parties are required to organise, strengthen and extend comprehensive habilitation and rehabilitation services and programmes to enable persons with disabilities to reach and maintain maximum independence, full inclusion and participation in all aspects of life as well as full physical, mental, social and vocational ability. The said article then clarifies that habilitation and rehabilitation services and programmes should begin at the earliest possible stage based on a multidisciplinary

48 United Nations General Assembly Resolution 106 (2007-01-24) UN Doc A/RES/61/106 18.

49 Hendriks and Lewis in Joly (ed) Routledge Handbook of Medical Law and Ethics (2014) 89.

50 Makgoba "The Report into the 'Circumstances surrounding the deaths of mentally ill patients: Gauteng Province'” (2017) 22.

51 Guernsey, Nicoli and Ninio http://siteresources.worldbank.org/SOCIALPROTECTION/ Resources/SP-Discussion-papers/Disability-DP/0712.pdf. 15. 
assessment of the individual's needs and strengths and that state parties are to promote the development of training for professionals and staff working in habilitation and rehabilitation services. In the absence of a definition of the term "rehabilitation", article 26 of the CRPD is to be read against the milieu of the Mental Healthcare Act 17 of 2002 that defines rehabilitation as "a process that facilitates an individual attaining an optimal level of independent functioning".

While it has been recognised in the Report that NGOs such as San Michele and Shammah House conducted workshops for the male and female patients and organised walks to a nearby shopping centre, respectively, in furtherance of patient rehabilitation; the Report also contains a deplorable acknowledgement that rehabilitation programmes were nonexistent in almost all NGOs, which was in the case of Precious Angels and thus attributed to a lack of experience and understanding in relation to managing adult patients.

\section{CONCLUSION AND RECOMMENDATION}

An appraisal of the events leading to the deaths of 144 Life Esidimeni Healthcare patients, as contained in the Report, and the provisions of the CRPD provide a prima facie indication of a violation by South Africa of various human rights provisions contained in the CRPD with specific emphasis on respect for inherent dignity and protecting the integrity of the person; equality and non-discrimination; the right to life; freedom from torture or cruel, inhuman or degrading treatment or punishment; freedom from exploitation, violence and abuse; health; an adequate standard of living; and habilitation and rehabilitation. The procedure for reporting violations by state parties against persons with disabilities, as contained in the CRPD Optional Protocol, as well as its non-compulsory nature are akin to armchair policing and may hinder the promotion of the overall spirit and purport of the CRPD. While the recent establishment of the Life Esidimeni arbitration hearings, led by retired Deputy Chief Justice Dikgang Moseneke, may provide temporary relief and closure for the families of the deceased; it has become apparent that persons with disabilities in South Africa require enduring implementation and accountability-focused interventions at a national and international level that take into consideration African-centric challenges and transcend policy development, approval and publication with the intention to practically improve the actual lives of persons with disabilities.

In light of the above, it is recommended that the government of South Africa utilises its constitutional framework, bolstered by existing mechanisms identified to monitor and evaluate disability transformation as set out in the WPRPD, as a catalyst create a body, with greater governmental clout and influence than the aforementioned Disability Unit, to rigorously police and monitor the interpretation and implementation of international law instruments such as the CRPD on a continuous basis. It is the author's considered view that such ongoing, national monitoring would contribute to weaving the importance of enforcing the Rights of Persons with Disabilities across the fabric of all sectors of South African society. 